\title{
Mobile Learning - Vilã ou Aliada dos Estudantes? Um estudo dos aspectos metodológicos de usabilidade de interfaces em dispositivos móveis
}

Mobile Learning - Villain or Student Ally? A Study about the methodological aspects of interface usability in mobile devices

COSTA, Karolina; Mestranda em Design; Universidade do Estado de Santa Catarina

karolina.nunnes@gmail.com

SANTOS, Flávio; Prof. Dr.; Universidade do Estado de Santa Catarina

flavioanvs@hotmail.com

\section{Resumo}

O presente estudo destina-se a investigar diferentes métodos de avaliação de usabilidade em dispositivos móveis, bem como evidenciar as principais heurísticas e recomendações propostas para o desenvolvendo de interfaces neste contexto. Apresenta-se então um panorama cronológico que inclui os resultados dos estudos de Jakob Nielsen, famigerado autor que realizou descobertas significativas voltadas à Interação-Homem-Computador, e posteriormente as guidelines sugeridas por Enrico Bertini, autor que vem aprofundando suas pesquisas na área de Interação-Homem-Mobile. A partir do levantamento teórico destes critérios ergonômicos, incorpora-se ao trabalho a análise crítica de três plataformas educacionais mobile, associando as características contidas em suas interfaces aos aspectos de usabilidade mencionados anteriormente pelos autores citados.

Palavras Chave: métodos; usabilidade; m-learning.

\begin{abstract}
The present study aims to investigate differents evaluation's methods of usability in mobile devices, as well as to highlight the main heuristics and recommendations proposed for the interfaces development in this context. It presents a chronological panorama that includes the results obtained by Jakob Nielsen, an infamous author who developed significant studies on Interaction-Man-Computer, and later the guidelines suggested by Enrico Bertini, a researcher who has been deepening his studies in the Interfaces Mobile's area. Based on the theoretical survey of these ergonomic criteria, we incorporate the critical analysis of three mobile educational platforms, associating the characteristics contained in their interfaces with the aspects of usability mentioned previously by the cited authors.
\end{abstract}

Keywords: methods; usability; m-learning. 


\section{Introdução}

A crescente inclusão das plataformas digitais de aprendizagem no cenário educacional atual vem modificando a maneira com a qual os estudantes têm acesso às informações. Sabe-se que cada vez mais os alunos estão cercados por estímulos tecnológicos, produtos digitais e agilidade na busca por conteúdos. Por este motivo torna-se imprescindível que profissionais e pesquisadores apliquem suas capacidades técnicas e intelectuais nos aspectos que se relacionam com a interatividade do sistema.

Muitas discussões têm sido levantadas a respeito do contexto tecnológico no qual a sociedade se insere atualmente. Somos constantemente impulsionados a crer que todos os processos envolvendo tarefas humanas serão substituídos e automatizados por sistemas digitalizados, que os artefatos virtuais assumem o lugar anteriormente ocupado por meios físicos e que a "era digital e do conhecimento" continuará provocando grandes transformações culturais e comportamentais no parâmetro social. De fato, a cibercultura que se enraíza amplamente em grande parte da extensão terrestre é fruto de uma relação estreita entre tecnologia e sociedade, no entanto se faz necessário compreender até que ponto as mudanças trazidas com o advento da tecnologia afetam positiva ou negativamente as práticas atuais, bem como entender em que medida as novas descobertas podem ser modificadas e aprimoradas.

É esta lacuna na qual baseia-se a presente pesquisa, pois considerando as transições e adaptações dos sistemas tradicionais de ensino para plataformas digitais, busca-se investigar também quais os estudos dentro do domínio da usabilidade mobile estão acompanhando esta evolução. Desta forma, pode-se deixar explícito os principais métodos e caminhos utilizados para tornar possível a prática do uso de plataformas mobile.

Pode-se dizer que dizer que o design de interfaces é capaz de ser responsável pelo sucesso ou fracasso de determinado sistema de comunicação, pois além de atrair o usuário por meio de uma estética agradável, ele desempenha o papel de unir e comunicar um conjunto de elementos essenciais como: usabilidade, identidade visual, padrões de navegação, arquitetura da informação, transição de telas, etc. Segundo Nielsen e Loranger, a usabilidade é um atributo de qualidade relacionado à facilidade de uso de algo. Refere-se a rapidez com que os usuários podem aprender a usar alguma coisa, a eficiência deles ao usá-la, o quanto lembram daquilo, seu grau de propensão a erros e o quanto gostam de utilizá-la (NIELSEN; LORANGER, 2007). Ainda usabilidade é definida como o fator que assegura que um produto ou serviço é fácil de usar, eficiente e agradável a partir do ponto de vista do usuário (PREECE; ROGERS; SHARP, 2007).

Para a investigação dos métodos e heurísticas de usabilidade de interfaces mais relevantes contidos nas bibliografias, utiliza-se uma pesquisa de caráter qualitativo-descritivo, onde se torna possível rastrear os referenciais teóricos existentes, selecionar e apresentar os conteúdos mais adequados, e por fim analisar sob um viés crítico, os resultados encontrados. 


\section{Métodos, Heurísticas e Recomendações de Usabilidade}

\subsection{Métodos para Avaliação de Usabilidade em Interfaces Gráficas}

De acordo com Jordan (1998), existem diversos métodos empíricos de avaliação que podem ser facilmente aplicados à usabilidade, como é o caso das técnicas que possuem origem na psicologia (questionários, entrevistas, focus group, etc). No entanto o autor afirma que três métodos de avaliação de usabilidade foram desenvolvimentos exclusivamente para a análise de usabilidade em interfaces gráficas digitais. São eles: Co-descoberta (co-discovery), Percurso Cognitivo e Registro de Uso (logging-use). Tais métodos possuem práticas independentes e trazem resultados diferenciados.

\subsubsection{Co-descoberta (co-descorvery)}

Este método é praticado em dupla, onde os dois participantes envolvidos na tarefa exploram juntos as interfaces digitais e podem de forma colaborativa descobrir como concluir as atividades propostas pelo sistema. Segundo Jordan (1998), observando o diálogo entre os participantes, o pesquisador pode obter uma melhor compreensão dos aspectos de usabilidade que envolvem as interfaces. Os integrantes da tarefa devem preferencialmente ser amigos, ou no mínimo se conhecerem, desta forma ficam menos inibidos ao verbalizar sobre o que estão fazendo e quais problemas estão enfrentando ao navegar entre as interfaces.

Jordan (1998) destaca que o pesquisador pode interagir com os participantes de duas formas. Primeiramente, pode posicionar-se juntos à eles enquanto os mesmos estiverem explorando os recursos da interface, ou questiona-los sobre o que estão pensando e como estão desempenhando as atividades. Outra forma de acompanhar os resultados é instruir os participantes antes do início da atividade e em seguida ausentar-se da sala, alocando-se em uma sala de observação para registrar por vídeo os acontecimentos. As instruções podem ser tanto de caráter geral, para possibilitar que todos os recursos da interface sejam explorados, quanto de caráter específico, onde são solicitadas tarefas individuais.

\subsubsection{Percurso Cognitivo}

O objetivo do percurso cognitivo é investigar o caminho traçado nas interfaces sob o ponto de vista do usuário. De acordo com Jordan (1998), o investigador tenta realizar as tarefas como se fosse o próprio usuário, na intenção de compreender em quais estágios o usuário enfrenta dificuldades e quais os passos necessários para desempenhar determinadas funções. É importante ressaltar que as observações feitas pelo pesquisador se baseiam totalmente nas suas percepções sobre quais efeitos as interfaces deveriam causar nos usuários. Para melhorar a precisão dos resultados, é importante compreender certas características dos usuários, como suas habilidades cognitivas e expectativas com relação ao sistema.

Para Santos (2000), este método objetiva predizer o quanto as interfaces gráficas de um sistema facilitam os progressos do usuário no decorrer da sua utilização. Para isto, o pesquisador deve assumir a perspectiva do usuário e investigar os erros e inconsciências existentes no projeto da interface. Basicamente, é seguir o passo-a-passo sugerido pelo design das interfaces e avaliar a eficiência da usabilidade.

\subsubsection{Registro de Uso}

Ainda de acordo com Jordan (1998), por meio de um dispositivo de registro de tela é 
possível captar as interações entre o usuário e a interface. Neste método, os recursos e botões acionados pelo participante são automaticamente registrados e ficam disponíveis para consultas posteriores. O uso desta técnica permite que o pesquisador colete informações sobre o desempenho dos usuários diante de determinados aspectos da interface, bem como auxiliar na detecção do número de vezes em que um recurso foi acionado.

A interpretação dos resultados neste método requer uma análise mais detalhada. Jordan (1998) explica que caso algumas funções da interface não sejam acionadas, ou acionadas poucas vezes, pode-se compreender o ocorrido a partir de três explicações. Primeiramente, o aspecto da interface pode não ter sido considerado útil para o participante, justificando então a baixa frequência de uso. De forma oposta à primeira explicação, a função pode ter sido considerada útil pelo usuário, no entanto a mesma possui dificuldades de uso. Por último, existe a possibilidade de o usuário não ter notado a existência desta determinada função durante o percurso cognitivo na interface.

\subsection{Recomendações para Criação de Interfaces em Dispositivos Computacionais}

Um dos requisitos básicos a se considerar durante a projeção de um sistema de interação é colocar-se no lugar do usuário, esta prática facilita a compreensão das limitações de usabilidade e também dos aspectos positivos trazidos por meio do percurso cognitivo gerado no sistema. Segundo Nielsen (1999), esse é o maior erro dos programadores, pois preocupam-se muito com os recursos técnicos e processos gráficos, não dando a devida importância aos usuários.

A partir do surgimento do termo usabilidade, diversos estudos foram gerados para dar suporte ao desenvolvimento de interfaces, a maioria destes estudos indicam métodos que podem ajudar na implementação de sistemas e plataformas digitais. Para que se possa realizar uma avaliação sobre a usabilidade de uma plataforma ou sistema, é necessário o conhecimento de heurísticas, um grupo de problemas que precisam ser identificados em termos de usabilidade, de design, e aspectos técnicos dos sistemas. (Fernandez, 2007). Em termos históricos, o precursor no desenvolvimento de heurísticas de usabilidade, Jakob Nielsen, tornou-se referência no domínio da World Web Wild. Nielsen (1994), propõe um conjunto de dez heurísticas recomendadas para plataformas web. Estes estudos serviram de base para diversas outras contribuições futuras no âmbito do design de interfaces.

1. Visibilidade do status do sistema: o sistema deve frequentemente manter os usuários informados sobre o que está acontecendo, por meio de feedback adequado em tempo razoável.

2. Correspondência entre o sistema e o mundo real: o sistema deve se utilizar de termos familiares aos usuários, com palavras, frases e conceitos claros, ao invés de termos específicos de programação

3. Controle do usuário e liberdade: de forma recorrente os usuários acionam funções e botões do sistema por engano, sendo assim precisam buscar a "saída de emergência" sem ter que passar por um extenso diálogo. Igualmente a função desfazer e refazer.

4. Consistência e padrões: os usuários não devem precisar analisar se palavras diferentes, situações ou ações possuem o mesmo significado. Siga as convenções da plataforma. 
5. Prevenção de erros: mais importante do que boas mensagens de erro é projetar um design que se preocupa em impedir que o erro aconteça em primeiro lugar.

6. Reconhecimento em vez de rechamada: o usuário não deve ter que se lembrar de informações a partir de uma parte do diálogo para outra. Instruções para a utilização do sistema devem ser visíveis ou facilmente recuperáveis sempre que apropriado.

7. Flexibilidade e eficiência de utilização: o sistema de permitir que usuários para adequem as ações frequentes.

8. Estética e design minimalista: os diálogos devem ser sempre simples e diretos, não devem conter informação que é irrelevante ou raramente necessária.

9. Ajude os usuários a reconhecer, diagnosticar e recuperar de erros: as mensagens de erro devem ser expressas em linguagem simples (sem códigos), indicar com precisão o problema e sugerir uma solução construtiva.

10. Ajuda e documentação: a documentação do sistema deve estar sempre visível ao usuário, mesmo que a plataforma seja simples de utilizar. Toda informação deve ser de fácil pesquisa, focada na tarefa do usuário, e não ser muito grande.

Ainda, durante a atividade de design, de um projeto IHC, algumas guidelines são essenciais para bons projetos de interação. A maneira como projetamos a interface deve conter guidelines (recomendações), que visam diminuir conflitos entre usuários envolvidos na aplicação (PREECE; ROGERS; SHARP, 2005). De acordo com Shneiderman (1998) existem oito regras valiosas a se considerar no domínio de interfaces:

1. Esforce-se pela consistência: posicione menus sempre no mesmo canto e do mesmo lado da tela. Para cada ação que possa resultar em perda de dados, peça confirmação da ação, e ofereça aos usuários a oportunidade de mudar de ideia.

2. Possibilite que usuários frequentes utilizem atalhos: por exemplo, em processadores de texto, os usuários podem se movimentar pelas funções utilizando menus, teclas de atalho ou botões de funções.

3. Ofereça feedback informativo: deixe claro o que o erro significa, considerando os diferentes tipos de usuários e seus significados.

4. Projete diálogos para encerrar as ações: deixe claro quando uma ação foi realizada com sucesso.

5. Ofereça prevenção contra erros e seu fácil manuseio: erros são inevitáveis, e o sistema deve perdoar os cometidos e possibilitar que o usuário volte atrás. 
6. Permita uma reversão fácil das ações: ofereça uma tecla desfazer (undo) sempre que possível.

7. Forneça suporte para um local interno de controle: os usuários se sentem mais confortáveis se percebem que estão no controle da interação, em vez da máquina.

8. Reduza a carga de memória de curto prazo: sempre ofereça aos usuários opções, em vez de exigir que se lembrem das informações quando mudarem de uma tela para outra.

\subsection{Usabilidade em Dispositivos Móveis}

Os estudos sobre ergonomia e questões de usabilidade em plataformas tradicionais encontram-se atualmente mais avançados se comparados com as pesquisas realizadas na área de usabilidade mobile. Isso porque o mercado de dispositivos móveis aqueceu depois do mercado de computadores pessoais já estar consolidado (Jl et al. 2006). Sendo assim, nota-se que diferentemente das plataformas web, poucos registros bibliográficos são encontrados mencionando uma lista de recomendações para a criação de interfaces mobile. Bertini et al. (2006), no entanto, aprofundou seus estudos no domínio da usabilidade em dispositivos móveis para tentar preencher esta lacuna, obtendo resultados significativos. A partir de um refinamento das regras de Nielsen e adaptação aos recursos das interfaces mobile, o autor desenvolveu oito recomendações aplicáveis à este contexto, apresenta-se a seguir estas oito regras de Bertini et al (apud NETO; 2013):

1. Visibilidade do status do sistema e facilidade de encontrar o dispositivo móvel. 0 sistema deve sempre manter o usuário informado sobre o que está ocorrendo. Além disso, o sistema deve dar prioridade a mensagens relativas a aspectos críticos do sistema, como capacidade da bateria, condições do ambiente de utilização e informações de conectividade. Tendo em vista que dispositivos móveis são perdidos com certa facilidade, medidas de encriptação de dados devem ser consideradas e o sistema deve prover formas de o usuário encontrar o dispositivo, caso ele tenha sido esquecido fora de lugar.

2. Compatibilidade entre o sistema e o mundo real. Permita que o usuário entenda a informação sendo exibida de forma correta, por meio de uma disposição de elementos em ordem natural e lógica. Sempre que possível, o sistema deve permitir identificar condições ambientes locais e informações de uso automaticamente e exibi-las de forma adequada ao usuário.

3. Consistência e mapeamento. O modelo conceitual que o usuário possui acerca da relação entre função e interação deve ser consistente com o contexto de utilização. É crucial que haja um mapeamento adequado entre ação a ser realizada e modo de realizar esta mesma ação no mundo real.

4. Boa ergonomia e design minimalista. Dispositivos móveis devem ser fáceis de manusear com apenas uma das mãos e ser resistentes a degradação por ações do ambiente, como umidade. Além disso, nenhuma informação desnecessária deve ser exibida ao usuário. 
5. Facilidade de entrada de dados, legibilidade e capacidade de assimilação. Os dispositivos móveis devem prover modos simples para que o usuário informe dados de entrada, preferencialmente sem que o usuário precise usar as duas mãos para executar tal tarefa. A tela deve possuir todas as informações visíveis ao usuário, independentemente das condições de luminosidade do ambiente. Idealmente, o usuário deve ser capaz de assimilar a informação sendo exibida imediatamente.

6. Flexibilidade, eficiência de uso e personalização. Permita que os usuários personalizem as ações de acordo com as necessidades deles. Sempre que possível, o sistema deve ser capaz de sugerir ao usuário formas de personalizar ações que porventura sejam benéficas em algum contexto de utilização.

7. Convenções estéticas, sociais e de privacidade. Leve em consideração aspectos emocionais e estéticos dos usuários que utilizarão o dispositivo. Assegure que as informações do usuário serão mantidas com segurança e privacidade. As interações devem respeitar convenções sociais dos usuários.

8. Gerenciamento de erros realístico. Proteja o usuário dos erros de interação. Se não for possível fazê-lo, permita que o usuário identifique o erro, o diagnostique e, se possível, o corrija. Mensagens de erros devem ser claras e sucintas. Se o erro for irreversível, certifique-se que o usuário entenderá a condição em que ele ocorreu. (NETO; 2013)

\subsection{Plataformas Educacionais e Fatores Ergonômicos}

Figura 1: Interfaces Gráficas do Aplicativo "MecFlix”

\section{Qabeat \\ CIÊNCIAS DA \\ NATUREZA E SUAS \\ TECNOLOGIAS}

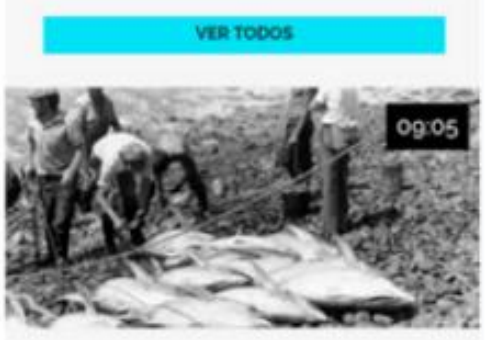

Ciclo da matéria

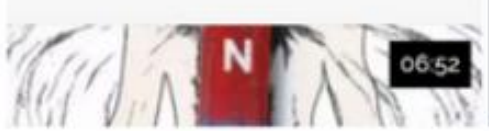

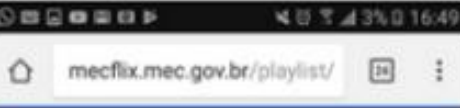

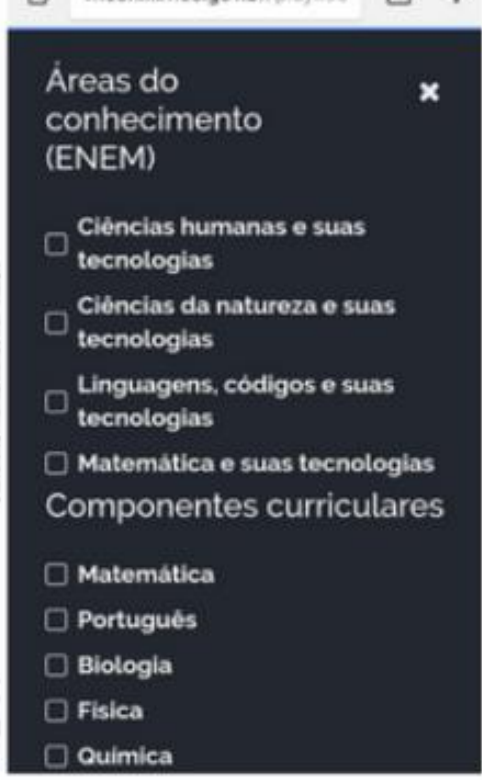

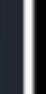

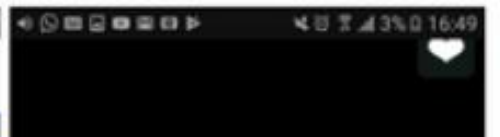

II

*v

Fonte: http://usemobile.com.br 
Figura 2 - Interfaces Gráficas do Aplicativo “Me Salva”

Início
(9) Ensino Médio
(4) Enem e Vestibulares
(5) Negôncias da Saúde
(9) Concursos
(9) Cursos Rápidos

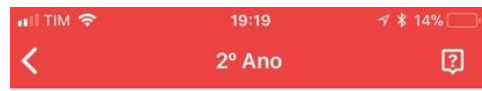

Q Buscar nesta página

\begin{tabular}{|c|c|}
\hline$\stackrel{10}{=}$ & $\begin{array}{l}\text { Redação } \\
18 \text { aulas } 0 \text { exercicios } 274 \text { min }\end{array}$ \\
\hline$(405$ & $\begin{array}{l}\text { Português } \\
51 \text { aulas } 98 \text { exercicios } 532 \mathrm{~min}\end{array}$ \\
\hline & $\begin{array}{l}\text { História } \\
55 \text { aulas } 130 \text { exercicios } 578 \text { min }\end{array}$ \\
\hline (1) & $\begin{array}{l}\text { Geografia } \\
93 \text { aulas } 119 \text { exercícios } 1562 \text { min }\end{array}$ \\
\hline & $\begin{array}{l}\text { Biologia } \\
100 \text { aulas } 168 \text { exercicios } 919 \text { min }\end{array}$ \\
\hline $2=0$ & $\begin{array}{l}\text { Química } \\
145 \text { aulas } 175 \text { exercicios } 1073 \mathrm{~min}\end{array}$ \\
\hline ceete & $\begin{array}{l}\text { Física } \\
106 \text { aulas } 83 \text { exercicios } 802 \mathrm{~min}\end{array}$ \\
\hline (4) & $\begin{array}{l}\text { Matemática } \\
135 \text { aulas } 112 \text { exercicios } 1008 \text { min }\end{array}$ \\
\hline
\end{tabular}

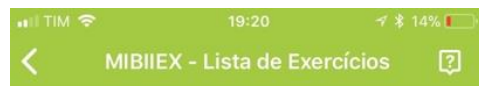

Questão 1/20

Com relação as proposições associadas a parede celular, julgue a alternativa incorreta:

É uma estrutura complexa, semi-rígida, que confere forma a célula bacteriana

Previne a ruptura da célula quando a pressão osmótica é maior dentro que fora

As micoplasmas não apresentam parede celular, e sim, uma camada de esteróis, cuja confere rigidez

Peptídeoglicanos são formados a partir de uma unidade básica de repetição de dois sacarídeos, o ácido $\mathrm{N}$-acetilmurâmico (NAM) e o ácido $\mathrm{N}$-acetilglicosamina (NAG)

\begin{tabular}{lcl} 
& ENVIAR RESPOSTA & \\
& Selecione uma resposta & \\
\hline Inicio & $\square$ & 000 \\
Meus Estudos & Ajustes
\end{tabular}

Fonte: https://play.google.com/store/apps/details?id=com.mesalva\&hl=pt_B

Figura 3 - Interfaces Gráficas do Aplicativo "GoConqr"

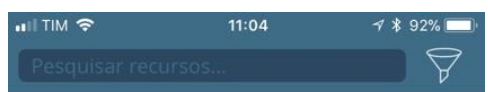

Rozenilde Oliveira no grupo Inglês - Recursos de Estudo começou a discussão:

Site de Gramática Inglesa

Site para estudantes e professores de inglês, com dicas de gramática e outros assuntos.

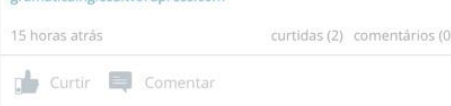

Grupos sugeridos para você com base no seu perfil

(28) Dicas e Estratégias de Estudo

Engenharia: Estudantes e Engenharia. Estud
Profissionais

Arycia Machado no grupo Inglês - Recursos de Estudo começou a discussão:

Praticar Inglês

Boa tarde!
Sou professora de Português/Inglês. Além da faculdade, concluí o esquecido muitas coisas, Estou pres das escolas ébasico, tenn interesse em praticar a lingua Inglesa. Podemos montar um grupo

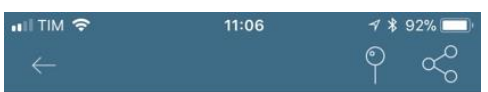

\section{Mecânica}

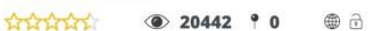

Notas em Mecânica, criado por Alessandra S. em 23-07-2013.

$$
\text { Notas por Alessandra S. }
$$

\section{Recursos relacionados}

Oscilações, ondas, óptica e radiação

(9) Quiz por Sem Parar

Plano de estudos ENEM - Parte 2 *Exatas/Biológicas

(3) Conjunto de Slides por GoConqr suporte

Fórmulas de física

Baralho de FlashCards por Alessandra S
7258 i0

Cinemática Escalar: Conceitos

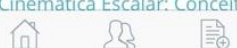

\section{Questionário - Tabela Periódica dos Elementos}

Pergunta: 2 de 6

Selecione uma das seguintes opções: A Figura 1 representa um extrato da Tabela Periódica do qual constam alguns elementos químicos. O número de eletrões do átomo do elemento flúor (F) é:

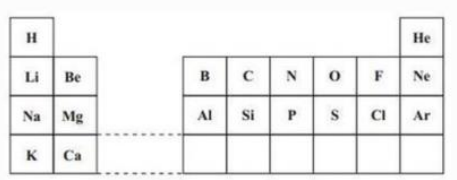

Figura 1

Pontos: 10

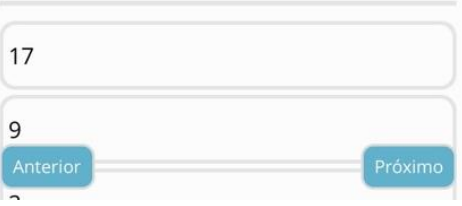

Fonte: https://play.google.com/store/apps/details?id=com.examtime.android\&hl=pt_BR 
A figura 1 ilustra o aplicativo Mecflix, uma plataforma desenvolvida pelo governo brasileiro com o intuito de incentivar e auxiliar estudos de caráter preparatório para o ENEM (Exame Nacional do Ensino Médio). O nome semelhante ao popular servidor de entretenimento Netflix não é coincidência, pois assim como a plataforma de vídeos, o app de estudos também oferece um streaming de vídeos, onde o aluno é capaz de acessar conteúdos didáticos e também ser membro de EAD (Educação à Distância) para assistir aulas diariamente. Algumas das regras expostas por Bertini et al. (2006), podem ser visualizadas no projeto de interfaces do aplicativo, como a "compatibilidade entre o sistema e o mundo real", pois a disposição dos elementos segue uma ordem natural e lógica, nota-se também a "facilidade de entrada de dados, legibilidade e capacidade de assimilação", pois a tela possui todas as informações visíveis aos usuários e não requer que o mesmo utilize duas mãos para realizar tarefas. Outra característica visível é "consistência e mapeamento", encontradas na boa relação entre ação e interação, a qual reflete o modo de uso no mundo real. O gráfico abaixo ilustra os itens de usabilidade identificado nas interfaces da plataforma.

Gráfico 1 - Aspectos de Usabilidade presentes no aplicativo "MecFlix"

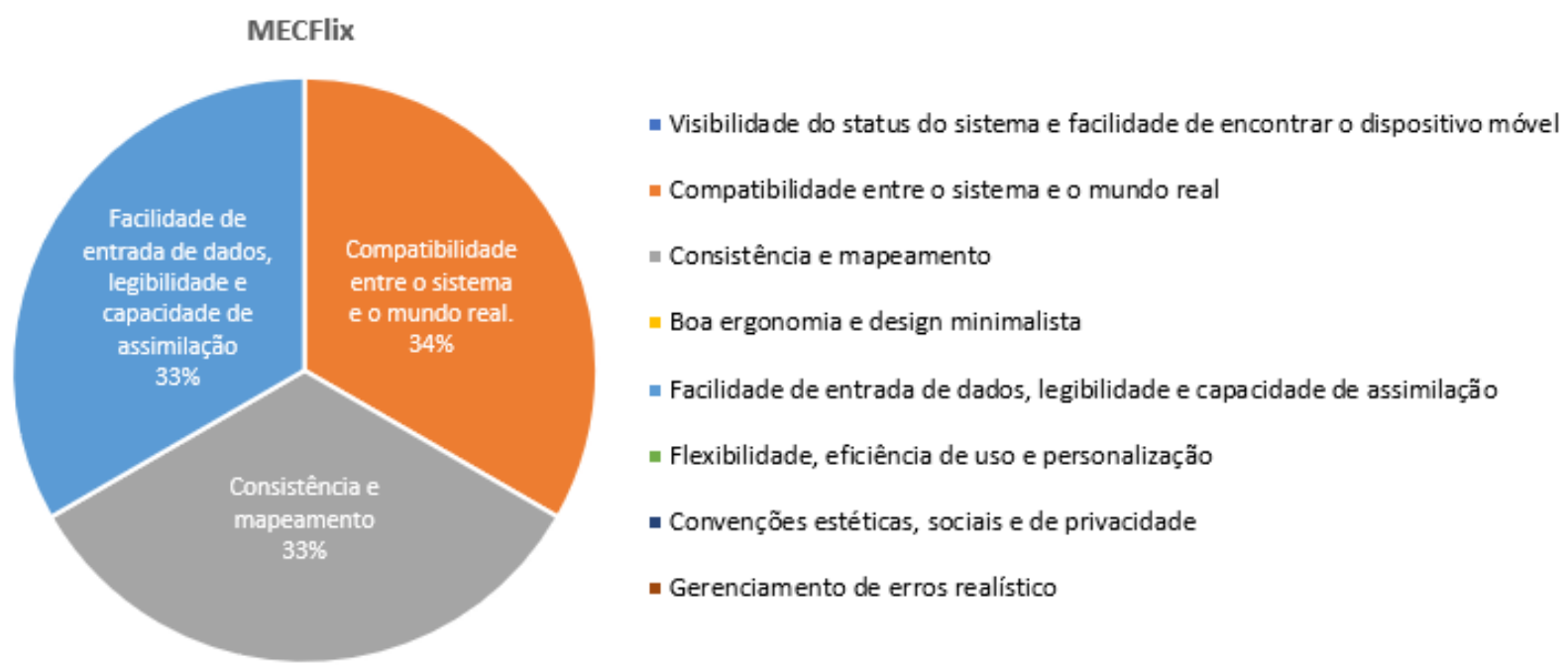

Fonte: Elaborado pelos autores

Já na figura 2 apresenta-se o aplicativo "Me Salva". Além de cursos preparatórios para o ENEM, o software oferece também aulas de reforço para alunos do ensino médio e superior, disponibilizando aulas online/off-line e listas de questões. As disciplinas e atividades oferecidas para o ensino médio correspondem à Redação, Português, História, Geografia, Biologia, Química, Física e Matemática. Para o ensino superior apresentam-se conteúdos de Ciências da Saúde, Engenharia e Negócios. É interessante notar que as mesmas regras de Bertini et al. (2006) presentes no aplicativo anterior também constam neste app. Além destas, é possível constatar a presença de mais algumas das "regras de ouro" de Bertini (2006) no conjunto de interfaces do aplicativo. A plataforma possui "visibilidade do status do sistema e facilidade de encontrar o dispositivo móvel", pois o sistema mantém o usuário informado sobre o que está acontecendo fora do âmbito do aplicativo (capacidade de bateria, condições do ambiente, informações de conectividade, etc.). Outro aspecto importante citado por Bertini (2006) e encontrado neste software é a "boa ergonomia e design minimalista", pois nenhuma informação desnecessária é 
exibida em tela, todos os elementos são de fácil entendimento. Mais uma caraterística interessante é a de seguir as "convenções estética, sociais e de privacidade", pois leva em consideração os aspectos emocionais e sociais do público alvo, incluindo ícones de boa legibilidade e facilmente compreensíveis pelo senso comum, além da preocupação com design contemporâneo que se adeque às expectativas do usuário. A seguir, apresenta-se um gráfico destacando as recomendações de usabilidade mobile contidas nas interfaces, a legenda evidencia também os recursos não contidos nesta plataforma.

Gráfico 2 - Aspectos de Usabilidade presentes no aplicativo "Me Salva“

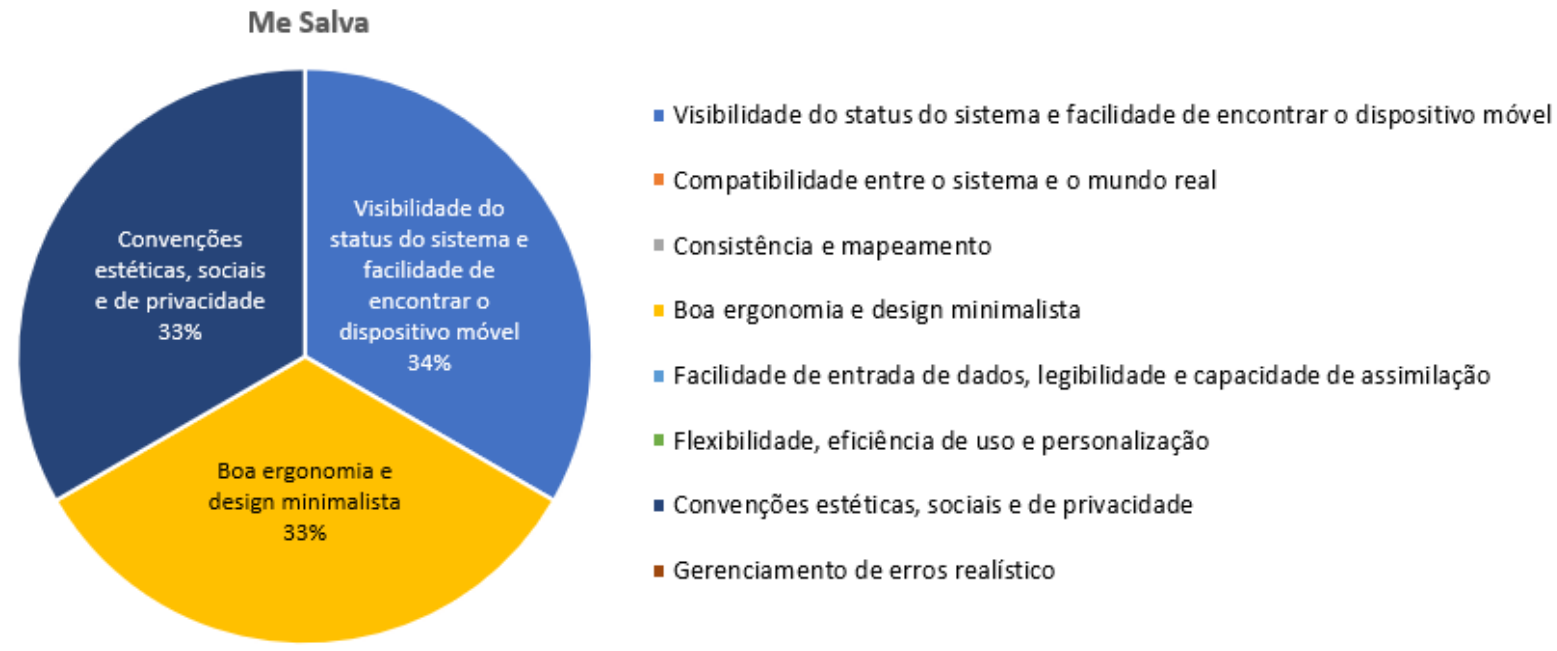

Fonte: Elaborado pelos autores

O terceiro grupo de interfaces corresponde ao aplicativo "GoConqr", um software de conhecimento colaborativo, onde alunos e professores compartilham recursos didáticos interativos, como: mapas mentais, quizzes, flashcards, slides, dentre outros. Esta plataforma funciona como uma rede social, pois possui um feed de atividades que exibe conteúdos publicados por outras pessoas de acordo com o interesse do usuário. Do ponto de vista ergonômico as interfaces gráficas deste aplicativo apresentam algumas inconsistências. A densidade informacional pode dificultar a assimilação dos recursos oferecidos pelo sistema, outro ponto marcante é a iconografia, que apesar de se utilizar de minimalismo e design moderno, não utiliza elementos de fácil compreensão, demandando maior tempo para que o usuário domine todas as ferramentas. O tamanho das tipografias textuais também representa um ponto crítico, pois em determinadas partes pode exigir esforço por parte do usuário para realizar a leitura. Dentre as recomendações destacadas por Bertini et al., o software apresenta um bom "gerenciamento de erros realísticos", pois permite que usuário identifique erros e volte atrás na ação. Outro aspecto positivo é a "visibilidade do status do sistema e facilidade de encontrar o dispositivo móvel", pois assim como aplicativo anterior, o layout da tela permite que o usuário visualize informações externas, como: horário, porcentagem de bateria, conectividade, etc. $\mathrm{O}$ gráfico abaixo apresenta de forma ilustrativa os dois aspectos da usabilidade que se destacaram positivamente na avaliação. 
Gráfico 3 - Aspectos de Usabilidade presentes no aplicativo "Go Conqr"

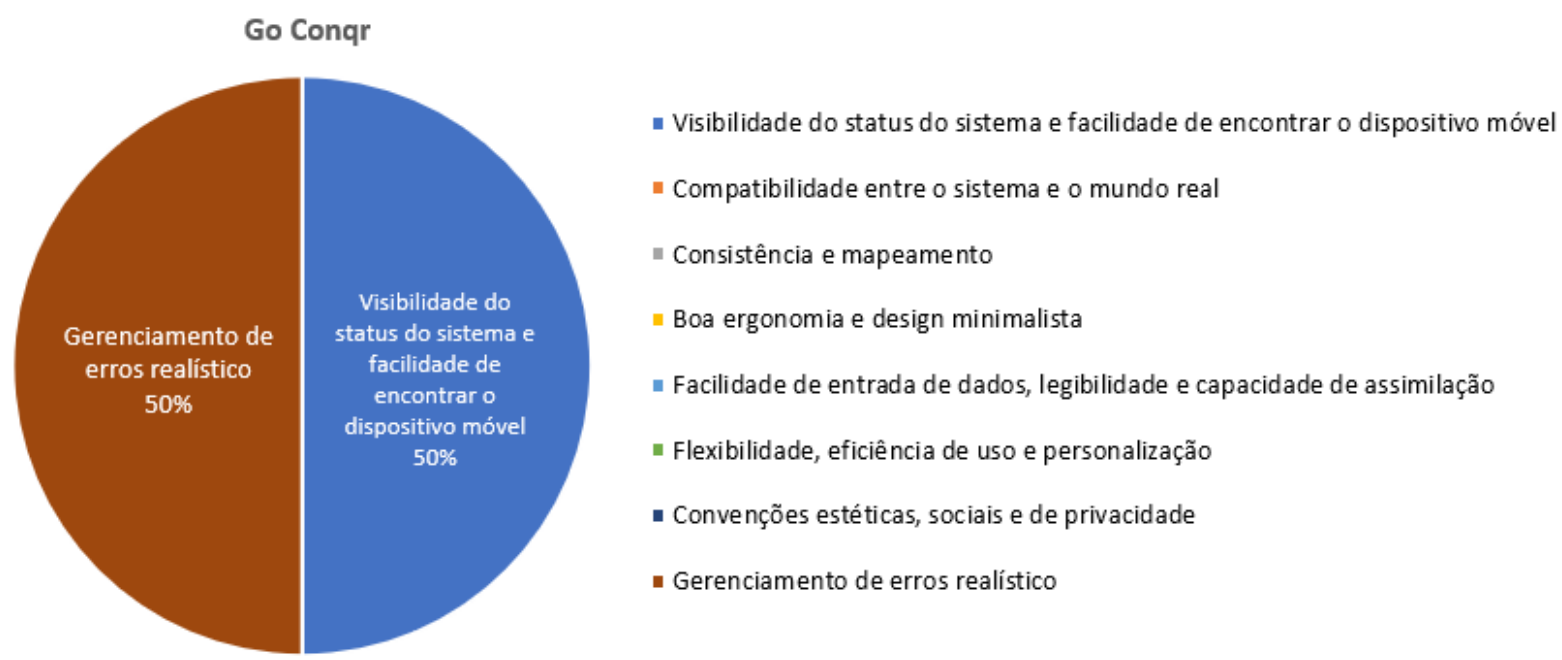

Fonte: Elaborado pelos autores

\subsection{Visão Pedagógica sobre o M-Learning}

Como mencionado anteriormente, diversas escolas têm aderido aos dispositivos móveis para auxiliar a aprendizagem dentro e fora da sala de aula. Assim, o aparelho vem sendo reconhecido também como objeto de aprendizagem (TAROUCO et al., 2004). Os docentes que lidam com esta ferramenta são profissionais capazes de avaliar quais as consequências trazidas pelo uso do m-learning no âmbito educacional. De acordo com uma professora integradora do projeto PALMA (Programa de Alfabetização na Língua Materna), o qual propõe auxiliar jovens e adultos no desenvolvimento da leitura e escrita básica por meio de uma plataforma digital, o uso de smartphones:

[...] diminuiu os índices de evasão e o aumento da frequência em sala de aula. "Eles tentam faltar menos, se preocupam em não deixar de fazer a atividade. Tornaram-se mais responsáveis", avalia a professora. Mas o principal diferencial em relação às aulas tradicionais, segundo ela, é que os alunos estudam por mais tempo (OJEDA, 2012).

Corroborando com a afirmação anterior a respeito dos aspectos positivos trazidos com a tecnologia móveis, Moura e Carvalho (2009) expressam: as tecnologias móveis ampliam o tempo e o espaço de estudo ao quebrar as barreiras temporais e espaciais, visto que o aluno pode aceder ao material de estudo em diversos momentos e contextos (MOURA; CARVALHO, 2009). O professor de ensino superior e sociólogo Marco Silva também expõe uma visão positiva com relação à adesão da tecnologia no sistema de ensino, afirmando:

A dinâmica e as potencialidades da interface on-line permitem ao professor superar a prevalência da pedagogia da transmissão. Na interface, ele propõe desdobramentos, arquiteta percursos, cria ocasião de engendramentos, de agenciamentos, de significações. Ao agir assim, estimula que cada participante faça o mesmo, criando a possibilidade de coprofessorar o curso com os aprendizes (SILVA, 2003).

Sob a ótica de Faccioni Filho (2008), o m-learning oferece alguns privilégios aos estudantes, como a mobilidade do dispositivo e a facilidade em aprender e qualquer lugar, seja no ambiente 
de convívio ou nas redes sociais. A ferramenta disponibiliza também a possibilidade de criar imagens, vídeos e textos que podem ser anexados aos sistemas de comunicação. Já para Paes e Moreira (2007), a capacidade limitada da baterias e a falta de portabilidade do dispositivo são características desfavoráveis à aprendizagem presentes nas plataformas m-learning.

\section{Conclusão}

Os estudos de usabilidade apontados nesta pesquisa indicam a existência diversos caminhos, técnicas e métodos de avaliação de interfaces gráficas em dispositivos digitais. Os resultados alcançados por Jakob Nielsen há algumas décadas atrás corroboraram para o sucesso de futuras descobertas no âmbito das tecnologias móveis. De forma semelhante, Ben Shneiderman também contribui amplamente para o desenvolvimento dos recursos interativos computacionais, reformulando as heurísticas de Nielsen e trazendo à tona novas perspectivas para implementação de interfaces. Bertini et al. (2006) foi capaz de sintetizar por meio de oito recomendações, os principais passos para desenvolver uma plataforma móvel que atenda as necessidades do usuário de forma satisfatória e sem incongruências.

Por meio da análise de três softwares de aprendizagem diferentes, constatou-se que na prática muitas das proposições de Enrico Bertini são encontradas nestas plataformas, o que sob um ponto de vista ergonômico agrega um aspecto positivo à elas. Pôde-se verificar também que algumas dificuldades podem acompanhar a prática da aprendizagem por meio de dispositivos móveis, como é o caso do esforço para a realização da leitura e compreensão de determinados percursos cognitivos.

De acordo com os docentes que lidam frequentemente com o sistema m-learning, o dispositivo móvel no auxílio da educação representa uma possibilidade de tornar os alunos mais responsáveis e interessados nas suas atividades escolares. Os professores destacam também que os dispositivos móveis podem potencializar o tempo de aprendizagem, visto que esta tecnologia móvel é capaz de transpor as barreiras do tempo e espaço.

Sendo assim, os resultados obtidos nesta pesquisa sugerem que o mobile learning desempenha um papel positivo na vida estudantil dos jovens, embora dotado de certas desvantagens, as plataformas digitais de aprendizagem auxiliam fortemente o acesso à conteúdos didáticos, simplificando a maneira com a qual alunos e professores buscam, compartilham e absorvem informações. 


\section{Referências}

BERTINI, E.; GABRIELLI, S.; KIMANI, S. (2006). Appropriating and Assessing Heuristics for Mobile Computing. In Proceedings of the Working Conference on Advanced Visual Interfaces, AVI '06, pages 119-126, New York, NY, USA.

FACCIONI FILHO, M. M-learning: tendências da educação com o uso de dispositivos moveis. 2008.

Ji, Y. G., Park, J. H., Lee, C., and Yun, M. H. A Usability Checklist for the Usability Eva- Iuation of Mobile Phone User Interface. International Journal of Human-Computer Interaction, 2006.

JORDAN, P. W. An Introduction to Usability. Londres: Taylor \& Francis Ltda., 1998.

MOURA, Adelina; CARVALHO, Ana Amélia. Peddy-paper literário mediado por telemóvel. Educação, Formação \& Tecnologias, vol.2, pp. 22-40, nov. 2009. Disponível em: $<$ http://eft.educom.pt.>.

NETO; Olibário José Machado. Usabilidade da Interface de Dispositivos Móveis: heurísticas e diretrizes para o design. Dissertação de Mestrado. USP - São Paulo, 2013.

NIELSEN, Jakob. Designing Web Usability: the practice of simplicity. USA: New Riders, 1999.

NIELSEN, Jakob. Ten usability Heuristics.1995.

NIELSEN, J.; LORANGER, H. Usabilidade na web: Projetando websites com qualidade.[S.I.: s.n.], 2007.

OJEDA, Igor. Uma vida nova na palma da mão. A Rede no 80, mai. 2012. Disponível em: $<$ http://www.arede.inf.br/inclusao/edicoes-anteriores/190-edicao-no-80-maio2012/5479-naescola-uma-vida-nova-na-palma-da-mao>

PAES, C.; MOREIRA, F. Aprendizagem com dispositivos móveis: aspectos técnicos e pedagógicos a serem considerados num sistema de educação. Porto: UPT, 2007. Disponível em:

$<$ http://grace.tech-x-pert.org/blogs/files/2007/06/aprendizagemcom-dispositivos-moveis-naaspectos-tecnicos-e-pedagogicos-aserem-considerados.pdf $>$.

PREECE, Jennifer; ROGERS, Yvonne; SHARP, Helen. Design de interação: além da interação homem-computador. Porto Alegre: Bookman, 2005.

PREECE, J.; ROGERS, Y.; SHARP, H. Design de Interação: Além do homem computador. [S.I.: s.n.], 2007.

SENA, Dianne; BURGOS, Taciana. O computador e o telefone celular no processo ensinoaprendizagem da educação física escolar. In: $3^{\circ}$ Simpósio Hipertexto e Tecnologias na Educação, 2010, Pernambuco.

SHNEIDERMAN, Ben. Designing the user interface: strategies for effective human computer interaction. 3. ed. Essex: AddisonWeslley, 1998.

SILVA, Marco. Sala de aula interativa. Rio de Janeiro: Quartet, 2003.

TAROUCO, Liane. M. R. et al. Objetos de Aprendizagem para M-Learning. Florianópolis: SUCESU Congresso Nacional de Tecnologia da Informação e Comunicação, 2004. 